\title{
Bilateral C-1 lateral mass reconstruction following radical resection of a giant osteoblastoma of the atlas: case report
}

\author{
Iulia Peciu-Florianu, MD, ${ }^{1}$ Gopalakrishnan Chittur Viswanathan, MCh, ${ }^{1}$ Juan Barges-Coll, MD, ${ }^{1}$ \\ Gabriel A. Castillo-Velázquez, MD, ${ }^{4}$ Pierre-Yves Zambelli, MD, PhD, ${ }^{2,3}$ and John M. Duff, MD ${ }^{1,3}$ \\ ${ }^{1}$ Neurosurgical Service, Department of Clinical Neurosciences and 2Division of Paediatric Orthopedics, University Hospital of \\ Lausanne; ${ }^{3}$ Faculty of Biology and Medicine, University of Lausanne, Switzerland; and ${ }^{4}$ Neurosurgical Service, Centro Médico \\ Puerta de Hierro, Guadalajara, Mexico
}

\begin{abstract}
Osteoblastoma is a rare, benign, osteoid-producing, and slow-growing primary bone tumor, typically arising in long bones or in the spine, with a slight male predominance. This report describes the surgical treatment of a giant C-1 (atlantal) osteoblastoma diagnosed in a young male patient with neurofibromatosis Type 1. The authors describe the clinical presentation, the surgical procedure for complete excision and stabilization, and results as of the 1-year follow-up. They detail a bilateral occipitoaxial spinal interarticular stabilization technique that they used after complete tumor excision. To the best of their knowledge, this is the first case of bilateral C-1 lateral mass reconstruction by this technique to be reported in the literature.
\end{abstract}

https://thejns.org/doi/abs/10.3171/2016.8.SPINE16319

KEY WORDS osteoblastoma; bilateral occipitoaxial spinal interarticular stabilization; C-1 lateral mass; neurofibromatosis Type 1; oncology

$\mathrm{O}$ STEOBLASTOMA is a rare, benign, osteoid-producing tumor, representing $1 \%$ of primary bone neoplasms. ${ }^{29}$ It is more frequent in young males (mean age at presentation 20.4 years, range 6 months to 75 years; male/female ratio $2: 1$ ), ${ }^{1}$ arising in the vertebral column in roughly $35 \%$ of cases. ${ }^{25}$

Clinically, osteoblastoma is a slow-growing lesion whose nidus size of $>1.5 \mathrm{~cm}$ differentiates it from the smaller osteoid osteoma. ${ }^{29}$ The most common clinical presentation is local pain.

For radiological diagnosis, CT scanning typically shows a bony lesion with cortical expansion and a radiolucent nidus. There can be surrounding bone rim sclerosis and multiple matrix calcifications, and more aggressive lesions can exhibit extensive bone destruction. MRI reveals soft-tissue extension, spinal cord or nerve root compression, and possible vascular compression due to tumor expansion. ${ }^{19,25}$

Diagnosis is usually confirmed by biopsy, and the treatment of choice, for all tumor stages, is a wide en bloc resection when technically feasible as an inadequate tumor margin is the main factor that negatively affects the prog- nosis. ${ }^{6,18}$ En bloc and marginal en bloc resection requires more extensive exposure to allow the surgeon access to the entire extent of the tumor.

In this report, we describe the treatment of an osteoblastoma diagnosed in a patient with known neurofibromatosis Type 1 (NF1). An association between osteoblastoma and NF1 has not been described and the relationship between the two is not certain in our case. We describe the surgical treatment of a giant osteoblastoma of C-1. Grosstotal intralesional resection of the tumor was performed and followed by bilateral occipitoaxial spinal interarticular stabilization (bOASIS) for reconstruction. Both vertebral arteries were preserved. The OASIS technique following tumor resection has been previously described by our group for unilateral lesions. ${ }^{4}$

\section{Case Report}

History

A 12-year-old boy with known NF1 presented with a 6-month history of progressive neck pain. Initial investi-

ABBREVIATIONS bOASIS = bilateral occipitoaxial spinal interarticular stabilization; $C V J=$ craniovertebral junction; NF1 $=$ neurofibromatosis Type $1 ;$ Oc $=$ occiput; VA $=$ vertebral artery.

SUBMITTED March 18, 2016. ACCEPTED August 26, 2016.

INCLUDE WHEN CITING Published online November 11, 2016; DOI: 10.3171/2016.8.SPINE16319. 

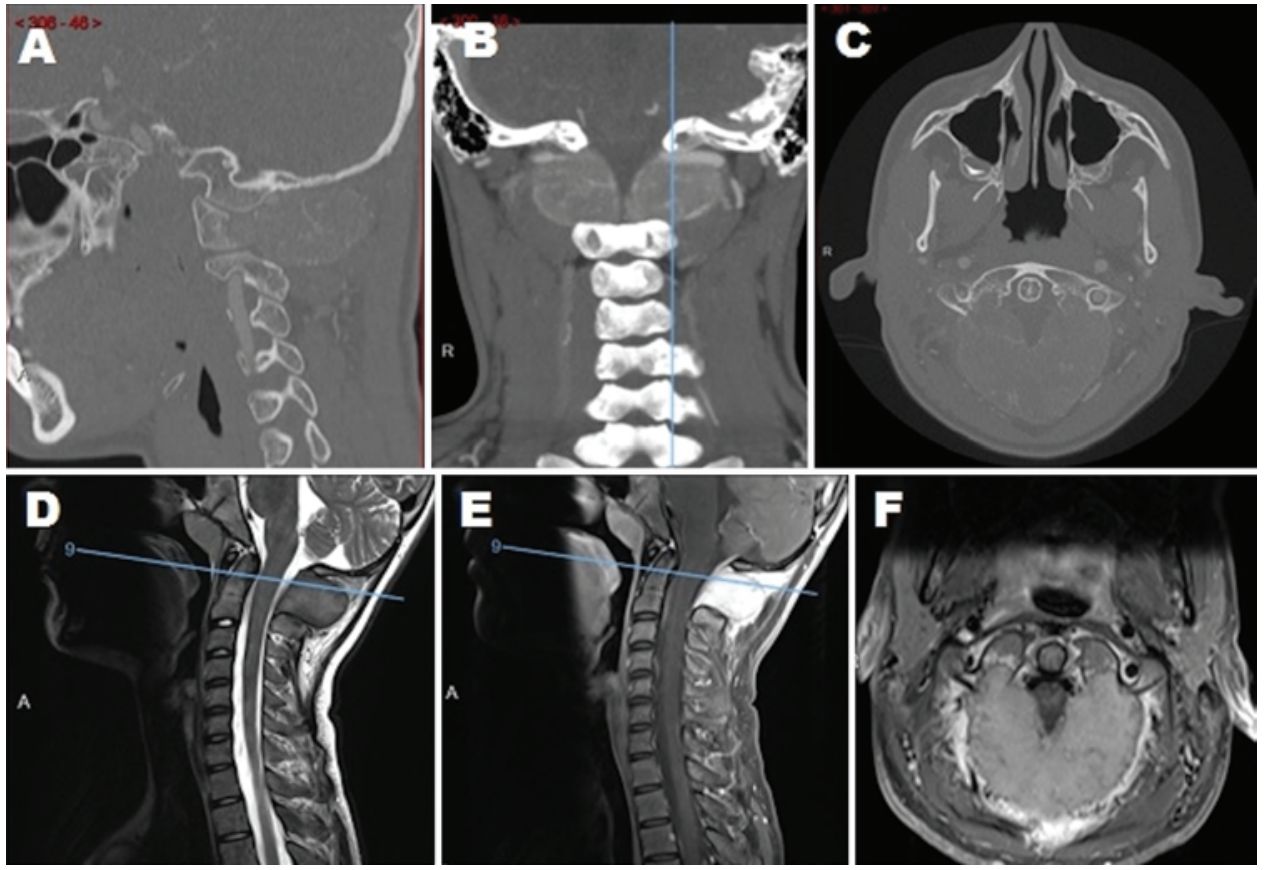

FIG. 1. A-C: Preoperative studies. Sagittal (A) and axial (C) CT scans showing destruction of the posterior arch and involvement of lateral masses of C-1. Coronal CT angiogram (B) showing displacement of the vertebral arteries. D-F: Sagittal T2-weighted (D) and T1-weighted $(E)$ and axial T1-weighted Gd-enhanced $(F)$ MR images showing a well-enhancing tumor with cord compression. Figure is available in color online only.

gation was done at an outside hospital with plain cervical radiographs, which were interpreted as normal. Cervical MRI, performed because of the patient's persistent neck pain, showed a mass centered on the posterior arch of C-1. The patient was then referred for surgical evaluation.

\section{Examination}

On physical examination the patient exhibited local tenderness in the C1-2 region at the nape of his neck and had limited neck movements, especially rotatory movements. General and neurological examinations showed normal findings.

Cervical CT scanning (Fig. 1A-C) revealed a giant (4 $\times 5.5 \times 2-\mathrm{cm}$ ) osteolytic tumor centered on the posterior arch of the atlas and extending into the lateral masses bilaterally. CT angiography showed that the tumor displaced the $\mathrm{V}_{3}$ segment of the vertebral arteries (VAs) rostrally, although both remained patent. MRI confirmed the presence of a contrast-enhancing lesion; spinal cord compression was seen at the level of C-1 with a focal area of cord hyperintensity (Fig. 1E and F). The tumor extended into the posterior portion of the $\mathrm{C}-1$ lateral masses bilaterally (Fig. 1C and F). Following multidisciplinary discussion, a mini-open biopsy was performed via a small midline posterior incision, and examination of the tissue confirmed the diagnosis of osteoblastoma. Because an en bloc resection was not considered to be technically feasible, a radical intralesional resection with reconstruction of the craniocervical junction was planned.

\section{Operation}

After induction of general anesthesia, the patient was positioned prone on a Jackson table and his head was stabilized in a neutral position using a Mayfield clamp. Neurophysiological monitoring was used during positioning and throughout the surgery.

An extension of the previous midline posterior approach was performed to expose the suboccipital region down to $\mathrm{C}-2$, including the posterior surface of the tumor. The mass was found to be firm and relatively avascular. Piecemeal intralesional radical excision was performed using the operating microscope. Both vertebral arteries (VAs) were identified during the resection and preserved, with a clear dissection plane between the tumor's capsule and the VA on either side. Portions of the tumor extending ventrally into the lateral masses of C-1 were resected completely using an ultrasonic bone scalpel, leaving only the anteriormost portion of the C-1 lateral masses (Fig. 2B). Following macroscopic gross-total resection of the tumor (Fig. 3), two appropriately sized titanium cages (Corridor, Globus Medical) were placed between the occipital condyles, whose convexities were drilled flat and cancellous bone exposed, and the superior facet surfaces of C-2 (Fig. 4). The cages were passed medial to the $\mathrm{V}_{2}$ segment and inferior to the $\mathrm{V}_{3}$ segment of the VA bilaterally such that no VA manipulation was necessary (see Fig. 4 for surgical details). Standard posterior instrumentation from the occiput (Oc) to the C-2 pedicles was then placed using image guidance (Fig. 4). A bone graft composed of autologous cancellous bone from the C-2 spinous process mixed with demineralized bone matrix putty (Grafton Putty, Osteotech, Inc.) was positioned inside and behind the cages bilaterally.

Somatosensory and motor evoked potentials remained normal throughout the procedure. Wound closure was performed in multiple layers in a standard fashion. 

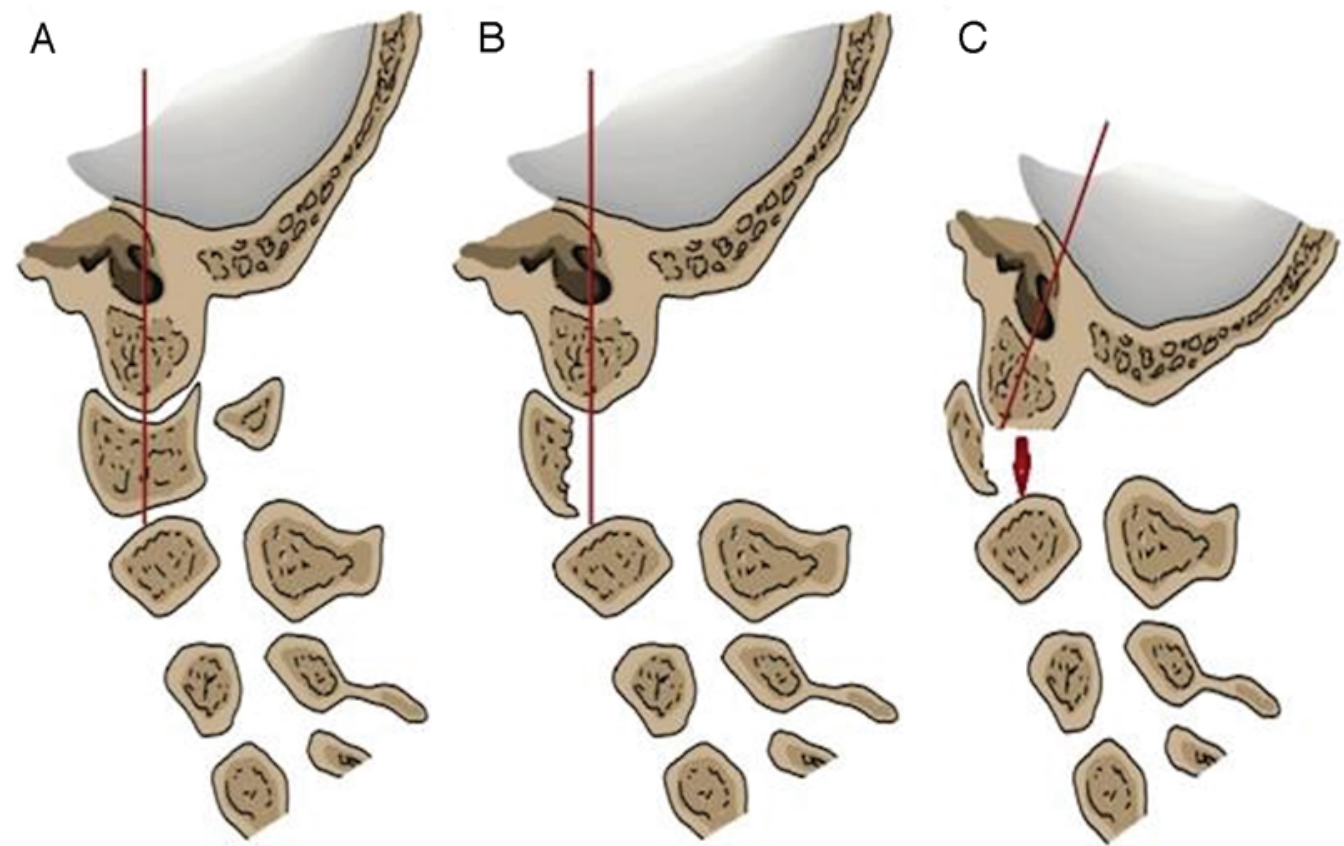

FIG. 2. Lateral view of the Oc-C1 joint, with the red line showing the "meridian" of the socket-ball joint. A: Normal Oc-C1 joint relation. B: Removal of the socket component of the joint. C: Downward and posterior slope of the condyle over the lateral mass. Copyright lulia Peciu-Florianu. Published with permission. Figure is available in color online only.

\section{Postoperative Course}

The postoperative course was uneventful. The patient was mobilized the day after surgery without any cervical collar. The histopathological analysis confirmed the diagnosis of osteoblastoma. Postoperative radiography, CT, and MRI were performed during the patient's hospital stay and at the 6- and 12-month follow-up examinations (Figs. 3 and 5). These confirmed gross-total resection. At the 12-month follow-up, imaging demonstrated no tumor recurrence, and the patient remained pain free $(0 / 10$ on the visual analog scale) and neurologically intact.

\section{Discussion}

Osteoblastoma represents a rare benign osseous neoplasm, first described alongside its histological analog, the osteoid osteoma. ${ }^{15,20}$ Osteoblastoma predominantly affects young males in their 2nd or 3rd decade, being twice as frequent in males as in females. Osteoblastoma affects the spine in $30 \%-40 \%$ of cases, predominantly at the cervical level, ${ }^{33}$ arising in $85 \%$ of cases from the posterior elements, with a possible extension to the vertebral body. ${ }^{25}$ It has also been described specifically at the atlantoaxial level in children, but it remains a rarity in the spectrum of primary bone tumors. ${ }^{22}$

The association of osteoblastoma in a patient with known NF1 has not been described previously. To the best of our knowledge, this is the first described case of an osteoblastoma in a patient with NF1. This autosomal dominant neurocutaneous syndrome is associated with an increased incidence of a wide spectrum of benign and malignant tumors. There are reports of an association of osteosarcoma and NF1, due possibly to the loss of expression of neurofibromin, a product of the NF1 gene with an important role in the activation of ras protein and in the proliferation and differentiation of cells. ${ }^{7,12}$ Although rare, in


FIG. 3. Postoperative 12-month follow-up MR images: sagittal T1-weighted (A) and T2-weighted (B) and axial T1-weighted Gd-enhanced (C) images showing complete resection and satisfactory decompression. Figure is available in color online only. 

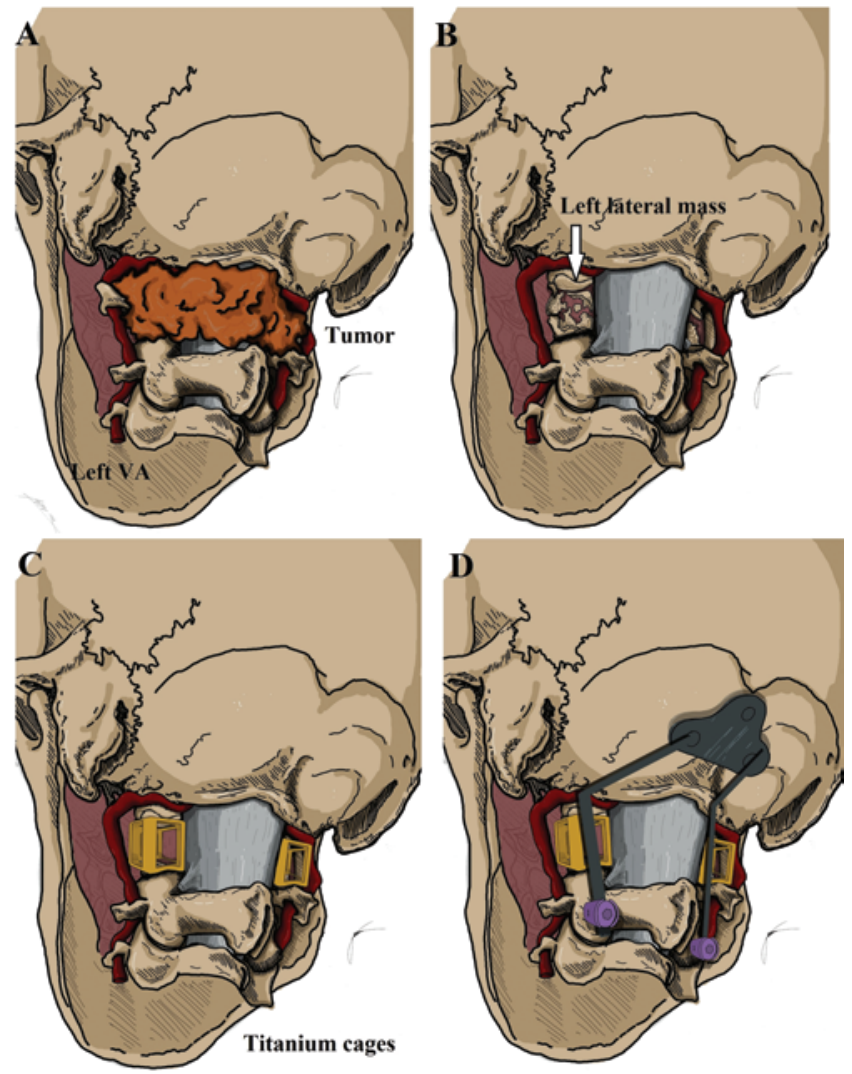

FIG. 4. Artist's view of the operative technique demonstrating initial tumor invasion $(\mathbf{A})$, total excision with drilling of $\mathrm{C}-1$ lateral masses $(\mathrm{B})$, Oc-C2 cage positioning (C), and final result after positioning of the occipital plate and C-2 transpedicular screws (D). Copyright lulia Peciu-Florianu. Published with permission. Figure is available in color online only.
non-NF1 patients, malignant transformation of osteoblastoma toward osteosarcoma has been described, especially after partial excision, and may be diagnosed years after the initial surgery. ${ }^{24,40}$ A subtype of osteoblastoma with aggressive features has been reported, with microscopic features that can blur the distinction with osteosarcoma. ${ }^{35}$ The main criterion for distinguishing an aggressive osteoblastoma is the presence of epithelioid osteoblasts; ${ }^{5}$ it also has a propensity for local invasion and higher recurrence rates These histological features were not found in our case.

From a surgical viewpoint, the main challenge for this case was adequate reconstruction following resection of the lateral masses of $\mathrm{C}-1$. This was achieved with bOASIS reconstruction and occipitocervical fixation with subsequent bone fusion. We felt it necessary to reestablish the load-bearing capacity of the head with the use of cages following extensive bone resection beyond the "prime meridian" of the occipitoatlantal joints (see Fig. 2).

Functionally, the craniovertebral junction (CVJ) is designed for maximal capital mobility to allow panoramic visualization of our surrounding environment. The two contained motion segments have very different biomechanical properties and roles in head movement. ${ }^{39}$ Stability is predicated primarily on intact ligaments, with osseous articulations designed for rotatory gliding motion between $\mathrm{C}-1$ and $\mathrm{C}-2$, and "hinge-like" motion between the Oc and C-1. The minimal bone constraints of these joints are subordinate to mobility requirements. Extensive literature exists regarding occipitoatlantal instability generated from condyle resection or tumor invasion. . $27,36^{2}$ Evidence addressing instability generated by $\mathrm{C}-1$ lateral mass tumor invasion or resection is lacking. The occipitoatlantal "ball and socket" joint allows flexion and ex-
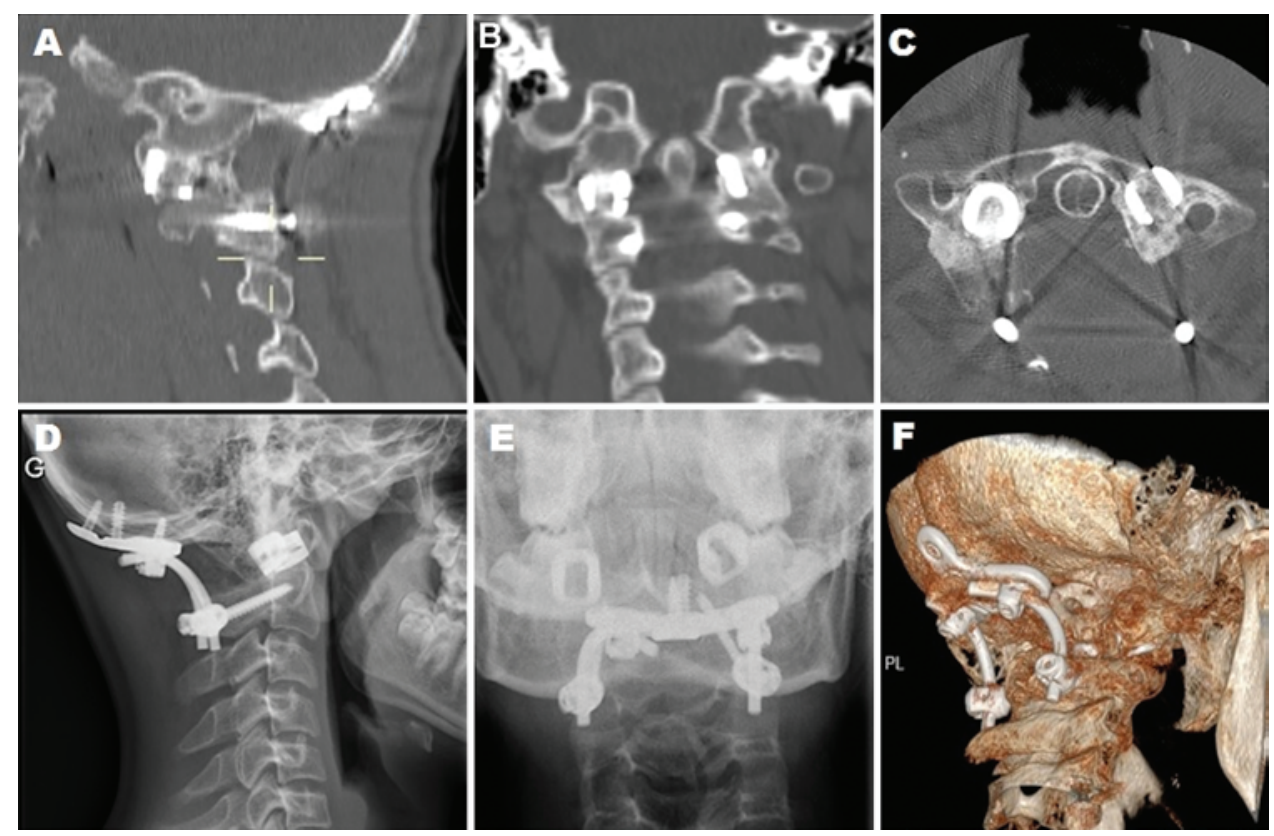

FIG. 5. Postoperative studies obtained at 12 months. Sagittal (A), coronal (B), and axial (C) MR images showing the position of the intraarticular cages and transpedicular C-2 screws, with fusion visible at the site of the Oc-C2 cages (intraarticular graft and on-lay graft). Lateral (D) and anteroposterior (E) radiographs and 3D CT reconstruction (F) showing hardware and anatomy. Figure is available in color online only. 
TABLE 1. Literature review of $\mathrm{C}-1$ lateral mass reconstruction

\begin{tabular}{lccccc}
\hline & \multicolumn{2}{c}{ Approach } & & \multicolumn{2}{c}{ Cage } \\
\cline { 2 - 3 } \cline { 5 - 6 } Authors \& Year & $\begin{array}{c}\text { Dual Lat \& } \\
\text { Posterior }\end{array}$ & $\begin{array}{c}\text { Posterior } \\
\text { Only }\end{array}$ & VA & & \\
Wang et al., 2009erved & Unilat & Bilat \\
\hline Chung et al., 2012 & & $\checkmark$ & $x$ & $\checkmark$ & \\
\hline Winking, 2014 & $\checkmark$ & & $x$ & $\checkmark$ \\
\hline Bobinski et al., 2015 & & $\checkmark$ & $\checkmark$ & $\checkmark$ & \\
\hline Present study & & $\checkmark$ & $\checkmark$ & & $\checkmark$ \\
\hline
\end{tabular}

tension, and the bony constraints resist translation in the sagittal plane. C-1 lateral mass resection beyond the meridian (Fig. 2A and B) removes the bony constraint of the "socket" and can result in the convex occipital condyle (ball) slipping posteriorly off the residual, down-sloping anterior portion socket of the C-1 lateral mass (Fig. 2C). Additionally, this bone resection likely renders the transverse ligament incompetent. The resultant loss of bone and ligamentous stabilizing constraints and loss of loadbearing capacity of the $\mathrm{C}-1$ lateral mass requires reconstruction and poses very specific challenges for fixation and reconstruction techniques. The intact lateral masses of $\mathrm{C}-1$ transmit the axial load from the occipital condyles through to the lateral masses of C-2. ${ }^{9}$ Moreover, ligamentous insertions on the lateral masses of $\mathrm{C}-1$, primarily the transverse ligament, play a vital role in atlantoaxial stability and maintain correct articular surface alignment. ${ }^{11,26,34}$ Older techniques such as posterior wiring for CVJ instability effectively resist flexion and extension but poorly resist rotation and translation, which may lead to secondary failure in arthrodesis. ${ }^{3}$ Different posterior construct techniques have been described to counteract rotational and translation forces, such as transarticular screws. ${ }^{14,17}$ CVJ reconstruction after partial or complete excision of the C-1 lateral masses has been described only in case reports (Table 1). ${ }^{4,8,37,38}$ Small case series in which longer constructs were used in the subaxial cervical spine have also been published. ${ }^{913}$ What is unusual in our case is the extensive resection of both lateral masses of $\mathrm{C}-1$, with loss of normal-load bearing capacity of the head. With regard to occipitoatlantal instability, reported case series and the biomechanics literature focus on the extent of occipital condyle resection, ${ }^{30,31,36}$ as well as on ligamentous integrity. ${ }^{10,23,32}$ Condyle-related instability is considered to be present with the development of an additional neurological deficit, a major deformity, and incapacitating mechanical pain after a condyle resection of greater than $75 \% .{ }^{30}$ Perez-Orribo et al. have shown that after an extensive resection of the condyle (i.e., $>75 \%$ ) range of motion at $\mathrm{Oc}-\mathrm{C} 1$ increases from $14.3^{\circ} \pm 2.7^{\circ}$ to $20.4^{\circ} \pm$ $5.2^{\circ}$ during flexion and from $6.7^{\circ} \pm 3.5^{\circ}$ to $10.8^{\circ} \pm 3.0^{\circ}$ during right axial rotation ( $\mathrm{p}<0.01)$, indicating the need for craniocervical fusion. ${ }^{27}$ Complex reconstruction of the CVJ using expandable cages when a C-2 spondylectomy is performed has also been described, demonstrating the reestablishment of anterior weight-bearing capacity with cages between $\mathrm{C}-1$ and $\mathrm{C}-2$, in conjunction with poste- rior constructs. ${ }^{16}$ Currently, biomechanical studies on reconstruction of C-1 lateral masses after destruction or resection are lacking. Nonetheless, in view of prior clinical studies describing reestablishment of load-bearing capacity of the head following C-2 spondylectomy, ${ }^{16,21,28}$ we thought it necessary in our case to reestablish head load-bearing capacity with addition of bOASIS cages in conjunction with a posterior construct, to enhance the likelihood of a durable arthrodesis.

\section{Conclusions}

In our case, we achieved a gross-total intralesional resection with a complete $\mathrm{Oc}-\mathrm{C} 2$ fusion without any complications at the 1-year follow-up.

The described bOASIS technique is an option that can be considered when bilateral C-1 lateral masses have been resected and should be complemented by the placement of a posterior occipitocervical construct.

\section{References}

1. Amirjamshidi A, Abbassioun K: Osteoblastoma of the third cervical vertebra in a 16-year-old boy: case report and review of the literature. Pediatr Neurosurg 46:396-401, 2010

2. Bejjani GK, Sekhar LN, Riedel CJ: Occipitocervical fusion following the extreme lateral transcondylar approach. Surg Neurol 54:109-116, 2000

3. Benzel EC: Biomechanics of Spine Stabilization. New York: McGraw-Hill, 1995

4. Bobinski L, Levivier M, Duff JM: Occipitoaxial spinal interarticular stabilization with vertebral artery preservation for atlantal lateral mass failure. J Neurosurg Spine 22:134-138, 2015

5. Britt JD, Murphey MD, Castle JT: Epithelioid osteoblastoma. Head Neck Pathol 6:451-454, 2012

6. Charles YP, Schuller S, Sfeir G, Steib JP: Cervical osteoblastoma resection and posterior fusion. Eur Spine J 23:711712,2014

7. Chowdhry M, Hughes C, Grimer RJ, Sumathi V, Wilson S, Jeys L: Bone sarcomas arising in patients with neurofibromatosis type 1. J Bone Joint Surg Br 91:1223-1226, 2009

8. Chung JY, Kim JD, Park GH, Jung ST, Lee KB: Occipitocervical reconstruction through direct lateral and posterior approach for the treatment of primary osteosarcoma in the atlas: a case report. Spine (Phila Pa 1976) 37:E126-E132, 2012

9. Clarke MJ, Zadnik PL, Groves ML, Sciubba DM, Witham TF, Bydon A, et al: Fusion following lateral mass reconstruction in the cervical spine. J Neurosurg Spine 22:139-150, 2015

10. Crisco JJ III, Oda T, Panjabi MM, Bueff HU, Dvorák J, Grob D: Transections of the C1-C2 joint capsular ligaments in the cadaveric spine. Spine (Phila Pa 1976) 16 (10 Suppl):S474S479, 1991

11. Debernardi A, D’Aliberti G, Talamonti G, Villa F, Piparo M, Collice M: The craniovertebral junction area and the role of the ligaments and membranes. Neurosurgery 68:291-301, 2011

12. Hatori M, Hosaka M, Watanabe M, Moriya T, Sasano H, Kokubun S: Osteosarcoma in a patient with neurofibromatosis type 1: a case report and review of the literature. Tohoku J Exp Med 208:343-348, 2006

13. Hsieh PC, Gallia GL, Sciubba DM, Bydon A, Marco RA, Rhines L, et al: En bloc excisions of chordomas in the cervical spine: review of five consecutive cases with more than 4-year follow-up. Spine (Phila Pa 1976) 36:E1581-E1587, 2011 
14. Huang DG, Hao DJ, He BR, Wu QN, Liu TJ, Wang XD, et al: Posterior atlantoaxial fixation: a review of all techniques. Spine J 15:2271-2281, 2015

15. Jaffe HL: Benign osteoblastoma. Bull Hosp Jt Dis 17:141151,1956

16. Jandial R, Kelly B, Bucklen B, Khalil S, Muzumdar A, Hussain M, et al: Axial spondylectomy and circumferential reconstruction via a posterior approach. Neurosurgery 72:300-309, 2013

17. Jeanneret B, Magerl F: Primary posterior fusion $\mathrm{C} 1 / 2$ in odontoid fractures: indications, technique, and results of transarticular screw fixation. J Spinal Disord 5:464-475, 1992

18. Kandziora F, Pingel A: Posterior-anterior resection of a cervical spine osteoblastoma. Eur Spine J 19:1041-1043, 2010

19. Li Z, Zhao Y, Hou S, Mao N, Yu S, Hou T: Clinical features and surgical management of spinal osteoblastoma: a retrospective study in 18 cases. PLoS One 8:e74635, 2013

20. Lichtenstein L: Benign osteoblastoma; a category of osteoidand bone-forming tumors other than classical osteoid osteoma, which may be mistaken for giant-cell tumor or osteogenic sarcoma. Cancer 9:1044-1052, 1956

21. Melcher RP, Harms J: Biomechanics and materials of reconstruction after tumor resection in the spinal column. Orthop Clin North Am 40:65-74, vi, 2009

22. Menezes AH, Ahmed R: Primary atlantoaxial bone tumors in children: management strategies and long-term follow-up. J Neurosurg Pediatr 13:260-272, 2014

23. Menezes AH, Traynelis VC: Anatomy and biomechanics of normal craniovertebral junction (a) and biomechanics of stabilization (b). Childs Nerv Syst 24:1091-1100, 2008

24. Merryweather R, Middlemiss JH, Sanerkin NG: Malignant transformation of osteoblastoma. J Bone Joint Surg Br 62:381-384, 1980

25. Orguc S, Arkun R: Primary tumors of the spine. Semin Musculoskelet Radiol 18:280-299, 2014

26. Panjabi M, Dvorak J, Crisco J III, Oda T, Hilibrand A, Grob D: Flexion, extension, and lateral bending of the upper cervical spine in response to alar ligament transections. J Spinal Disord 4:157-167, 1991

27. Perez-Orribo L, Little AS, Lefevre RD, Reyes PR, Newcomb AG, Prevedello DM, et al: Biomechanical evaluation of the craniovertebral junction after anterior unilateral condylectomy: implications for endoscopic endonasal approaches to the cranial base. Neurosurgery 72:1021-1030, 2013

28. Puttlitz CM, Harms J, Xu Z, Deviren V, Melcher RP: A biomechanical analysis of $\mathrm{C} 2$ corpectomy constructs. Spine J 7:210-215, 2007

29. Ropper AE, Cahill KS, Hanna JW, McCarthy EF, Gokaslan ZL, Chi JH: Primary vertebral tumors: a review of epidemiologic, histological, and imaging findings, Part I: benign tumors. Neurosurgery 69:1171-1180, 2011

30. Shiban E, Török E, Wostrack M, Meyer B, Lehmberg J: The far-lateral approach: destruction of the condyle does not necessarily result in clinically evident craniovertebral junction instability. J Neurosurg 125:196-201, 2016
31. Shin H, Barrenechea IJ, Lesser J, Sen C, Perin NI: Occipitocervical fusion after resection of craniovertebral junction tumors. J Neurosurg Spine 4:137-144, 2006

32. Steinmetz MP, Mroz TE, Benzel EC: Craniovertebral junction: biomechanical considerations. Neurosurgery 66 (3 Suppl):7-12, 2010

33. Trübenbach J, Nägele T, Bauer T, Ernemann U: Preoperative embolization of cervical spine osteoblastomas: report of three cases. AJNR Am J Neuroradiol 27:1910-1912, 2006

34. Tubbs RS, Salter EG, Oakes WJ: The accessory atlantoaxial ligament. Neurosurgery 55:400-404, 2004

35. Vigorita VJ, Ghelman B, Mintz D: Orthopaedic Pathology, ed 2. Philadelphia: Wolters Kluwer Health/Lippincott Williams \& Wilkins, 2008

36. Vishteh AG, Crawford NR, Melton MS, Spetzler RF, Sonntag VK, Dickman CA: Stability of the craniovertebral junction after unilateral occipital condyle resection: a biomechanical study. J Neurosurg 90 (1 Suppl):91-98, 1999

37. Wang VY, Deviren V, Ames CP: Reconstruction of C-1 lateral mass with titanium mesh cage after resection of an aneurysmal bone cyst of the atlas. J Neurosurg Spine 10:117-121, 2009

38. Winking M: Lateral mass lesions of the $\mathrm{C} 1$ vertebra: a modified "far lateral" approach. Eur Spine J 23 (Suppl 2):257261, 2014

39. Wolfla CE: Anatomical, biomechanical, and practical considerations in posterior occipitocervical instrumentation. Spine J 6 (6 Suppl):225S-232S, 2006

40. Woźniak AW, Nowaczyk MT, Osmola K, Golusinski W: Malignant transformation of an osteoblastoma of the mandible: case report and review of the literature. Eur Arch Otorhinolaryngol 267:845-849, 2010

\section{Disclosures}

Dr. Duff reports owning stock in KB Medical.

\section{Author Contributions}

Conception and design: Peciu-Florianu, Chittur Viswanathan, Barges-Coll, Castillo-Velázquez, Duff. Acquisition of data: PeciuFlorianu, Chittur Viswanathan, Zambelli, Duff. Analysis and interpretation of data: Peciu-Florianu, Chittur Viswanathan, Duff. Drafting the article: Peciu-Florianu, Chittur Viswanathan, BargesColl, Castillo-Velázquez, Duff. Critically revising the article: all authors. Reviewed submitted version of manuscript: all authors. Approved the final version of the manuscript on behalf of all authors: Peciu-Florianu. Study supervision: Chittur Viswanathan, Barges-Coll, Duff.

\section{Correspondence}

Iulia Peciu-Florianu, Neurosurgical Service, University Hospital of Lausanne (CHUV), Rue Bugnon, Lausanne 1010, Switzerland. email: iulia.peciu-florianu@chuv.ch. 